\title{
New Natural Coagulant Aid in Water Treatment
}

\author{
Jenny Siew Lee Chew ${ }^{1}$, Agnes Yin Yee Ho ${ }^{1}$, Boon Chin Lim ${ }^{1}$, Wai Loon Chan ${ }^{1}$, Yeek Chia \\ $\mathrm{Ho}^{1, *}$, Jun Wei $\mathrm{Lim}^{2}$, and Soon Onn Lai ${ }^{3}$ \\ ${ }^{1}$ Civil and Environmental Engineering Department, Universiti Teknologi PETRONAS, 32610 Bandar \\ Seri Iskandar, Perak Darul Ridzuan, Malaysia \\ ${ }^{2}$ Fundamental and Applied Sciences Department, Universiti Teknologi PETRONAS, 32610 Bandar \\ Seri Iskandar, Perak Darul Ridzuan, Malaysia \\ ${ }^{3}$ Chemical Engineering Department, Universiti Tunku Abdul Rahman, Jalan Sungai Long, Bandar \\ Sungai Long, 43000 Kajang, Selangor
}

\begin{abstract}
Natural source of coagulant is certainly being considered in addressing the disadvantages associated with the use of inorganic coagulants. Annona muricata is hypothesized to be new material as natural coagulant aid in coagulation-flocculation process. On the other hand, due to the high lipids content in microalgae, namely, Chlorella vulgaris is used in producing renewable energy, i.e. biodiesel. Coagulation-flocculation is an effective method in microalgae harvesting. Thus, in this study, a novel natural coagulant aid extracted from fruit waste in algae harvesting. It is aimed to (1) to extract natural coagulant aid (hereafter is known as biopolymer) extracted from Annona muricata seeds in algae harvesting, and (2) to evaluate the operational conditions of coagulation-flocculation process by utilizing the biopolymer. As a result, it is observed that acid extraction and extraction through sodium chloride does not show any yield. On the other hand, the harvesting efficiency showed positive response as coagulant aid at $20 \mathrm{mg} / \mathrm{L}$.
\end{abstract}

\section{Introduction}

Lately, the utilization of microalgae in biofuel production has caught much attention due to the high constituent of lipids content which can be used as feedstock to achieve high biofuel production rate. In addition to the contribution in biofuel production, residue of microalgae biomass, which is poor in lignin and rich in proteins and other compound of commercial interest, can be further processed and utilized in animal feed production and biorefinerybased production [1]. Consequently, microalgae harvesting becomes an important approach in order to separate the solid-liquid microalgae suspension for further downstream processes. Yet, the small size and a density similar to that of water result in microalgae scattering in water. Microalgae are hydrophilic and have a negative charged surface which prevent them from self-aggregation and thus keeping them in suspension [2] [2-4]. These characteristics of microalgae cause limitations in harvesting activity. To overcome the challenges in

\footnotetext{
* Corresponding author: yeekchia@yahoo.com; yeekchia.ho@utp.edu.my
} 
microalgae harvesting, several researches have been carried out concerning the methods in harvesting activity, primarily in the effort of microalgae mass recovery in water. Barros et al. (2014) and Laamanen et al. (2015) reported that a practical microalgae harvesting method should consume low energy, require minimum cost, allow water and nutrients recycle, achieve high biomass concentration, avoid the usage of toxic chemicals as well as occupying a small footprint.

The current and most promising harvesting methods include filtration, centrifugation, gravity sedimentation and coagulation-flocculation. However, each of this method has significant drawback in harvesting microalgae. Filtration method is slow and membrane fouling can be an associated problem which later causes high replacement and maintenance cost. Centrifugation, in addition, is the fastest harvesting method, yet is the most expensive and energy intensive operation. Possibility of cell damage due to high shear force may also be induced in centrifugation harvesting method. The highly suspended microalgae in water results in the unsuitability of gravity sedimentation method due to high consumption of time as well as the low concentration of algae cake produced. On the other hand, regardless of the high efficiency of coagulation-flocculation in microalgae recovery, the utilization of both organic and inorganic coagulants do produce certain drawbacks to the harvested microalgae. Low biodegradability and high cost are the associated disadvantages due to the usage of organic coagulant such as polyacrylamides whereas the inorganic coagulant, or chemical coagulant can contaminate the microalgae with toxic substances [3]. Thus, natural materials may serve as a viable alternative. Earlier, the utilization of natural (organic) coagulant in microalgae harvesting have been reported $[2,4-8]$. The commonly used natural coagulants are polyelectrolytes or polymers such as Moringa oleifera protein powder, Moringa oleifera seed powder, chitosan, a few to name. Pragya et al. [9] noted that the natural coagulant is less sensitive to $\mathrm{pH}$, requires low dosage, thus reducing the sludge quantity as well as contamination probability. In addition, natural coagulant is more effective with high charge density and is applicable to a wide range of microalgae species. Moreover, Hamid et al. [5] and Yang et al. [8] demonstrated the high practicability of natural coagulant utilization in microalgae harvesting by claiming that the harvesting efficiency using M. oleifera seed achieved $90 \%$ and above, comparing to the application of alum which yield only $34 \%$ of microalgae biomass recovery at the same dosage.

Therefore, this study aims to (1) extract biopolymer from Annona Muricata seeds as a source of natural coagulant aid in Chlorella vulgaris harvesting, and (2) evaluate the operational conditions of coagulation-flocculation process by utilizing the extracted biopolymer.

\section{Experimental}

\subsection{Extraction of Biopolymer}

Alkaline extraction method was conducted by varying the sodium hydroxide $(\mathrm{NaOH})$ concentration $(0.5 \mathrm{M}, 1.0 \mathrm{M}, 1.5 \mathrm{M})$, seeds to solvent ratio $(1: 30,1: 65,1: 100)$ and temperature $\left(40{ }^{\circ} \mathrm{C}, 60{ }^{\circ} \mathrm{C}, 80^{\circ} \mathrm{C}\right)$ as designed using Design Expert software, the optimum condition of extraction which produce the maximum yield of biopolymer was determined. 


\subsection{Assay of Flocculating Activity}

Relative concentration of microalgae in the suspension before and after coagulationflocculation process was measured with respect to the absorbance. The optical density (OD) at $680 \mathrm{~nm}$ was measured by Hach DR 6000 Spectrophotometer. The harvesting efficiency and turbidity reduction efficiency were computed according to Eq. (1) and (2).

$$
\text { Harvesting efficiency }(\%)=[(\mathrm{A}-\mathrm{B}) / \mathrm{A}] \times 100 \%
$$

where A is OD680 of the sample before treatment; B is OD680 of the sample after treatment.

As a comparison, turbidity of the samples was measured to determine the concentration of suspended particulates in the water. Turbidity removal efficiency was calculated as:

$$
\text { Turbidity removal efficiency }(\%)=[(\mathrm{X}-\mathrm{Y}) / \mathrm{X}] \times 100 \%
$$

where $\mathrm{X}$ is turbidity of the sample before treatment; $\mathrm{Y}$ is turbidity of the sample after treatment.

2-level factorial design was selected and there were three factors to be evaluated in biopolymer extraction. The $\mathrm{P}$ value (probability) with 95\% confidence level ( $\mathrm{P}$ value $<0.05$ ) was restricted so that the significance of each factor i.e. solvent molarity, seed to solvent ratio, temperature, and the interactions between factors could be identified precisely. Other than that, the regression line (coefficient of determination, $\mathrm{R}^{2}$ ) of at least 0.99 was designated for the ANOVA analysis to ensure the accuracy of data obtained.

\section{Result and Discussion}

\subsection{Statistical Analysis for the Interaction Effects of Biopolymer Extraction}

The significance of the three independent variables, (A) $\mathrm{NaOH}$ molarity, (B) seed to $\mathrm{NaOH}$ ratio, and $(\mathrm{C})$ temperature are determined using factorial design. The results demonstrate that seed to $\mathrm{NaOH}$ ratio as well as temperature are individually significant ( $\mathrm{p}$-value $<0.05$ ) whereas the interaction between solvent molarity and ratio as well as the interaction between ratio and temperature are significant variables in biopolymer extraction. The value of $\mathrm{R}^{2}$ in this experimental design is 0.9960 , suggesting that the model is well fit to the data. The ANOVA table is shown in Table 1.

Table 1. ANOVA table for $2^{3}$ factorial design

\begin{tabular}{|l|c|c|c|c|c|}
\hline & $\begin{array}{c}\text { Sum of } \\
\text { square }\end{array}$ & df & $\begin{array}{c}\text { Mean } \\
\text { square }\end{array}$ & -value & Remark \\
\hline Model & 142.29 & 7 & 20.33 & 0.0138 & Significant \\
\hline (A) NaOH molarity & 1.64 & 1 & 1.64 & 0.1382 & \\
\hline (B) Seed to NaOH ratio & 115.09 & 1 & 115.09 & 0.0025 & Significant \\
\hline (C) Temperature & 7.05 & 1 & 7.05 & 0.0380 & Significant \\
\hline AB & 12.21 & 1 & 12.21 & 0.0225 & Significant \\
\hline AC & 0.051 & 1 & 0.051 & 0.7140 & \\
\hline BC & 5.88 & 1 & 5.88 & 0.0451 & Significant \\
\hline ABC & 0.36 & 1 & 0.36 & 0.3746 & \\
\hline
\end{tabular}




\subsection{Assay of Microalgae Harvesting Efficiency}

Figure 1 (a) shows the effect of $\mathrm{pH}$ ranging from 3 to 10 in flocculation efficiency for harvesting $C$. vulgaris. The original $\mathrm{pH}$ of $C$. vulgaris before treatment was between $\mathrm{pH} 7$ to $\mathrm{pH}$ 8. The microalgae undergo auto-flocculation around this $\mathrm{pH}$ and the efficiency was $40 \%$ after 30 minutes of settlement. The efficiency increases to $73 \%$ after the $\mathrm{pH}$ is adjusted to 3 . Hence, the results indicate that the effective microalgae harvesting can be attained by reducing the $\mathrm{pH}$ up to 3 . However, studies have shown that microalgae can be autoflocculated at high $\mathrm{pH}$ due to the presence of metal cations such as calcium and magnesium ions in culture medium that can eventually form hydroxide precipitate with hydroxide ions in the water as $\mathrm{pH}$ increases [10,11]. Meanwhile, Hadjoudja et al. [12] studied the cell surface characteristics of microalgae and reported that the zeta potential of $C$. vulgaris is negative in water except at $\mathrm{pH} 3$ which is approximately zero. Zeta potential is a key indicator of the stability of colloidal dispersions. Stability of colloids increases with increasing zeta potential (either positive or negative). In other word, the zero-charged surfaces of $C$. vulgaris tend to flocculate as colloids with low zeta potential is unstable in water and has the high ability to form flocs [13]. In addition, the nutrients provided during cultivation were only phosphorus and nitrogen in this project, therefore, the auto-flocculation of $C$. vulgaris would not occur at high $\mathrm{pH}$ due to the absence of metal cations in the culture medium.

Effect of the extracted biopolymer addition in C. vulgaris harvesting is shown in Figure 1 (b). The highest harvesting efficiency of $40 \%$ is obtained when $35 \mathrm{mg} / \mathrm{L}$ of extracted biopolymer is dosed with $\mathrm{pH}$ adjusted to 4 . This is because the effect of biopolymer in flocculating C. vulgaris is hindered at $\mathrm{pH} 3$. Hence, to observe and interpret the efficiency of biopolymer in microalgae harvesting, $\mathrm{pH}$ is adjusted to 4 when conducting jar test. Further addition of biopolymer beyond $35 \mathrm{mg} / \mathrm{L}$ shows a declined efficiency at approximately $33 \%$. This indicates that the extracted biopolymer is overdosed which may be due to the excessive charges from biopolymer to interact with a small number of $C$. vulgaris cell. Similarly, the addition of alum (Figure 1 (c)) which yields the highest harvesting efficiency of $37 \%$ at concentration of $25 \mathrm{mg} / \mathrm{L}$ shows low efficiency of both alum and the extracted biopolymer in harvesting $C$. vulgaris. It is worth to note that the $\mathrm{pH}$ after flocculation by the extracted biopolymer increases to $4.3 \pm 0.1$, indicating the utilization of positive hydrogen ions present in acidic medium to bridge with the negatively charged $C$. vulgaris and form flocs. Nevertheless, when alum is added, the average increase in $\mathrm{pH}$ is 4.04 . Compared to the $\mathrm{pH}$ increase after treatment by the extracted biopolymer, it can be concluded that the utilization of hydrogen cations is replaced by the bridging between the positive $\mathrm{Al}^{3+}$ cations in alum and negatively charged C. vulgaris.

The effect of biopolymer dose in harvesting efficiency of $C$. vulgaris was investigated. Various concentration of alum $(0 \mathrm{mg} / \mathrm{L}, 5 \mathrm{mg} / \mathrm{L}, 10 \mathrm{mg} / \mathrm{L}, 15 \mathrm{mg} / \mathrm{L}, 20 \mathrm{mg} / \mathrm{L}, 25 \mathrm{mg} / \mathrm{L})$ were tested both with and without the addition of biopolymer (Figure 4. (d)). At concentration of $10 \mathrm{mg} / \mathrm{L}$, the harvesting efficiency achieved $80 \%$ with the addition of $20 \mathrm{mg} / \mathrm{L}$ biopolymer. The efficiency increases up to $90 \%$ when $25 \mathrm{mg} / \mathrm{L}$ of alum was added at the same concentration of biopolymer. Compared to the efficiency of $37 \%$ when only alum is added, the results demonstrate that addition of $20 \mathrm{mg} / \mathrm{L}$ extracted biopolymer could enhance the flocculating efficiency for harvesting $C$. vulgaris. Since the simultaneous utilization of both alum and the extracted biopolymer shows a significant effect in harvesting C. vulgaris, it can be concluded that the extracted biopolymer acts as a coagulant aid, improving the performance of alum in flocculation process. After the negative charge of microalgae cells have been destabilized by alum (cationic coagulant), the addition of extracted biopolymer as coagulant aid binds the microalgae cell surfaces together through bridging and forms flocs [14]. Tenney et al. [15] and Granados et al. [6] noted that anionic polymeric flocculant is not 
suitable for flocculation of freshwater microalgae including $C$. vulgaris because the negative charged microalgae surface prevents the anionic flocculant to form polymeric bridging, due to the repulsion between negative charges. Thus, alum is needed in this project to first destabilize the charges of $C$. vulgaris surface to enable the formation of flocs by the extracted biopolymer.

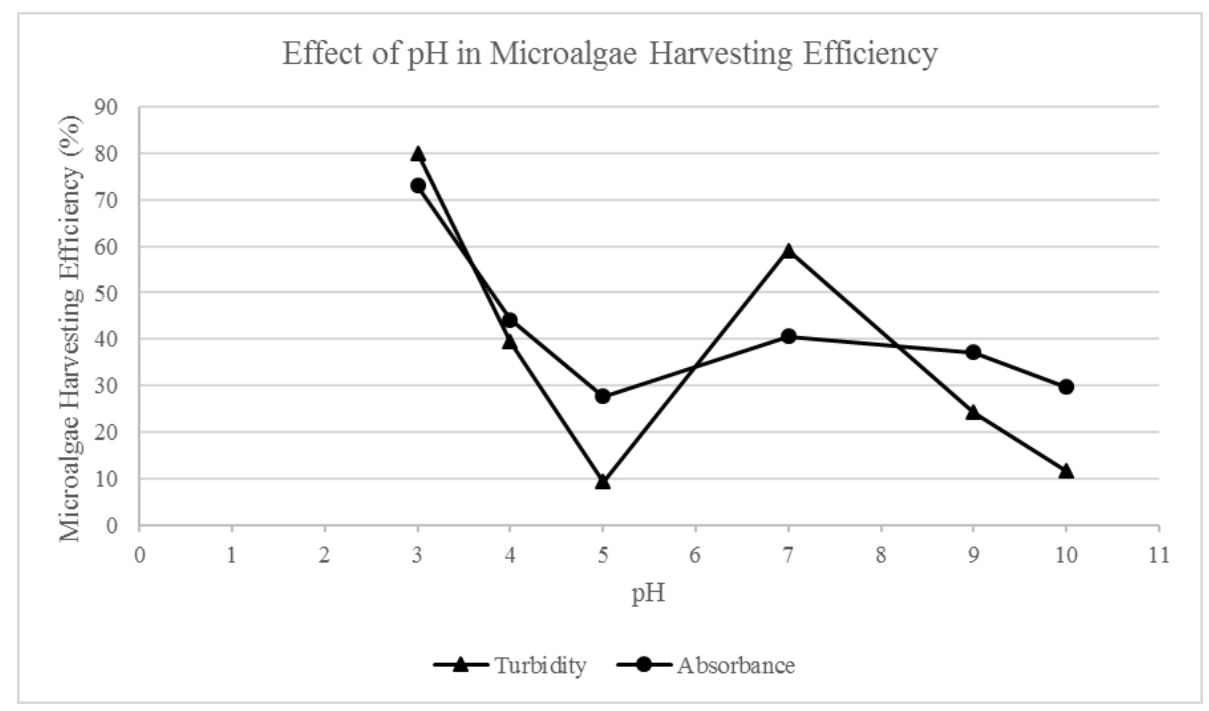

(a)

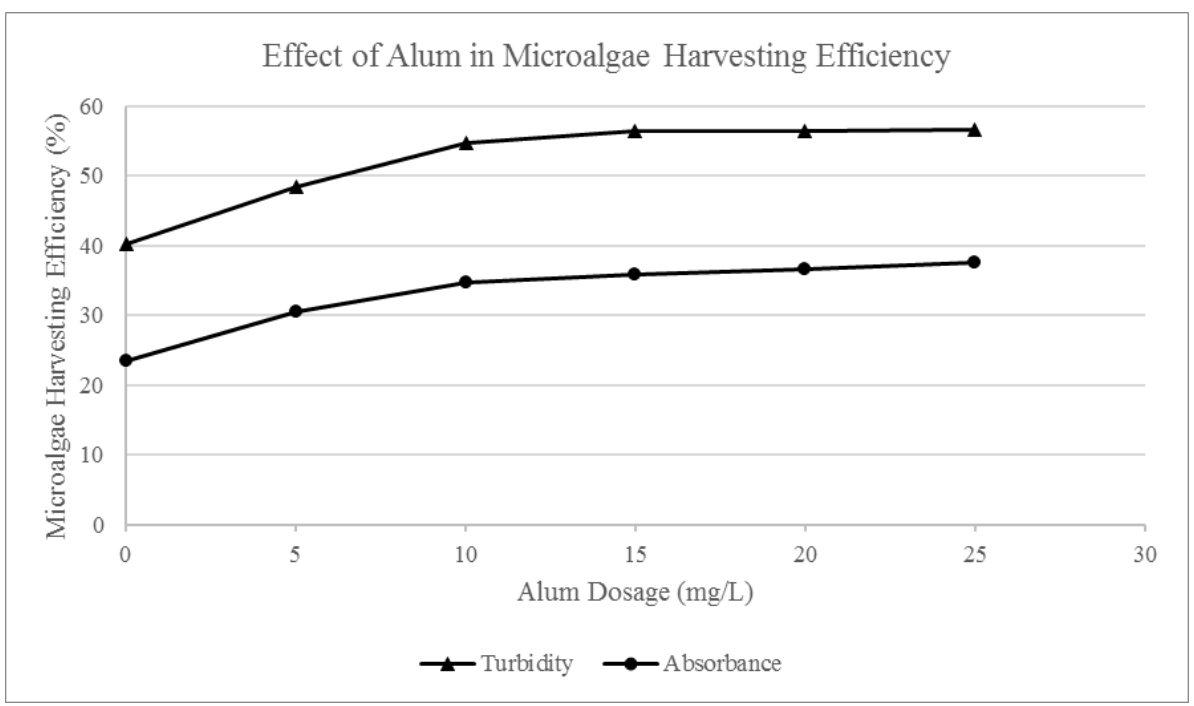

(b) 


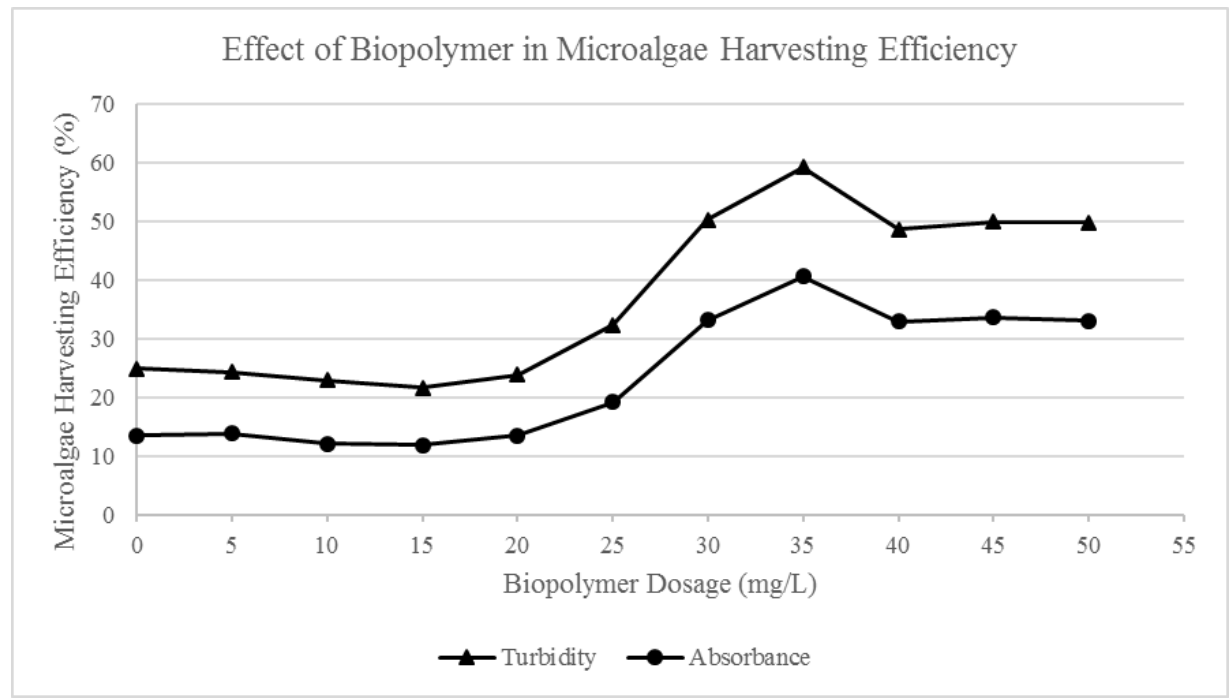

(c)

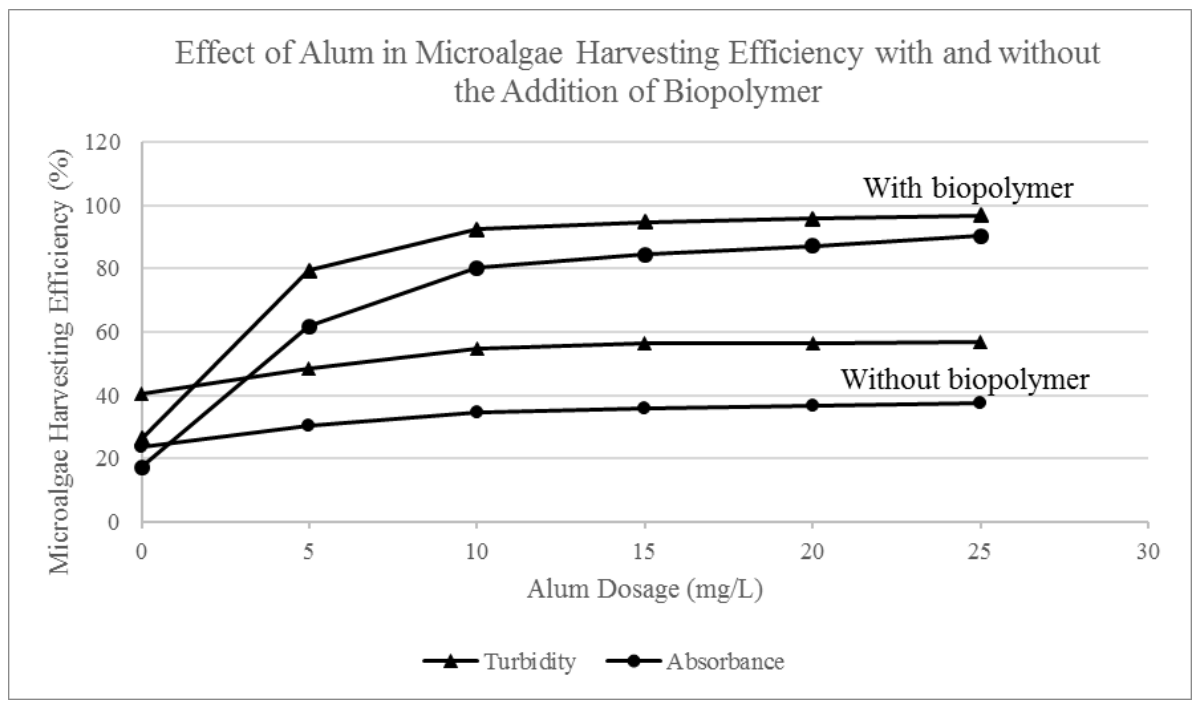

(d)

Fig. 1. Effects of $\mathrm{pH}$, alum and biopolymer in microalgae harvesting efficiency

\section{Conclusion}

In conclusion, the utilization of biopolymer extracted from A. Muricata seeds as source of coagulant aid is achieved. Both the Chlorella vulgaris suspension and the extracted biopolymer are likely to be characterized with respect to the functional group, zeta potential and surface morphology. Moreover, the microalgae harvesting efficiency using natural 
source of coagulant aid is up to $80 \pm 3 \%$ with the addition of $10 \mathrm{mg} / \mathrm{L}$ alum and the extracted biopolymer, respectively at $\mathrm{pH} 4$. Although alum poses the possibility of contamination to microalgae when use in harvesting, the concentration can be greatly reduced when the extracted biopolymer is added as coagulant aid.

\section{Acknowledgement}

The authors would like to express their gratitude on financial support for this project under YUTP grant (0153AA-E34).

\section{References}

1. A.I. Barros, A.L. Gonçalves, M. Simões, and J.C.M. Pires, Renewable and Sustainable Energy Reviews, 41, (2015)

2. J.A. Gerde, L. Yao, J. Lio, Z. Wen, and T. Wang, Algal Research, 3, (2014)

3. C.A. Laamanen, G.M. Ross, and J.A. Scott, Renewable and Sustainable Energy Reviews, 58, (2016)

4. S.H. Abdul Hamid, F. Lananan, W.N.S. Din, S.S. Lam, H. Khatoon, A. Endut, and A. Jusoh, International Biodeterioration \& Biodegradation, 95, (2014)

5. S.H. Abdul Hamid, F. Lananan, H. Khatoon, A. Jusoh, and A. Endut, International Biodeterioration \& Biodegradation, 113, (2016)

6. M.R. Granados, F.G. Acién, C. Gómez, J.M. Fernández-Sevilla, and E. Molina Grima, Bioresource Technology, 118, (2012)

7. R. Gutiérrez, F. Passos, I. Ferrer, E. Uggetti, and J. García, Algal Research, 9, (2015)

8. I.-S. Yang, E.-S. Salama, J.-O. Kim, S.P. Govindwar, M.B. Kurade, M. Lee, H.-S. Roh, and B.-H. Jeon, Energy Conversion and Management, 117, (2016)

9. N. Pragya, K.K. Pandey, and P.K. Sahoo, Renewable and Sustainable Energy Reviews, 24, (2013)

10. L. Chen, C. Wang, W. Wang, and J. Wei, Bioresource Technology, 133, (2013)

11. N. Sanyano, P. Chetpattananondh, and S. Chongkhong, Bioresource Technology, 147, (2013)

12. S. Hadjoudja, V. Deluchat, and M. Baudu, Journal of Colloid and Interface Science, 342, (2010)

13. R. Greenwood and K. Kendall, Journal of the European Ceramic Society, 19, (1999)

14. D. Vandamme, I. Foubert, and K. Muylaert, Trends in Biotechnology, 31, (2013)

15. M.W. Tenney, W.F. Echelberger, R.G. Schuessler, and J.L. Pavoni, Applied microbiology, 18, (1969) 